\title{
correspondence
}

\section{Scottish science}

SIR,-Martin Goldman's distaste for the idea of devolution in Scotland (17 March, page 208) should not let him mislead readers by saying that Scotland does well out of grant-giving bodies such as the Medical Research Council (MRC).

The MRC spends $8.6 \%$ of its budget in Scotland which has $9.7 \%$ of the UK population (Hansard 18 December 1975) and if the figure were based on the number of medical students or teaching staff it would be $17 \%$.

I am told by those who advise the MRC that the reason the Scottish figure is low is that Scottish applications are rare, and that the reason for this is that the Scots believe that the clever people in London are more deserving of the money. The only cure for this affliction of the spirit is devolution or federalism.

Finally, Dr Goldman's view that devolution or federalism cannot work will be read with amusement in North America.

Yours faithfully, D. N. M. Hamilton

Department of Surgery,

Western Infirmary,

Glasgow.

Scotland

\section{Nuclear irrationality}

SIR,--My brief essay "Nuclear Power, Public Interest and the Profesisonal"' was essentially a plea for critical rationality (and the consequent antiauthoritarian approach) in the way society evaluates nuclear power. Two letters $^{2,3}$, present critical comments which I think are partly irrational.

Dr Grantham makes several misleading statements. One example is the comment on small reactors and "bombcapacity commercial reactors" in relation to "a few microgrammes (of plutonium) can kill you". Another example is "the (nuclear) battle is onesided. Pronuclear propagandists are paid: the opposition is not". Apart from pointing to the falsehood in the latter part of this statement, I emphasise that I do not look at the nuclear debate as a battle. My essay was an attempt to get at the facts and to emphasise the need for a rational debate on all "sides".

Dr Grantham has also chosen to disregard completely almost all my basic points. $\mathrm{He}$ states that "nuclear industry representatives seem to want to exclude biologists, environmentalists and the general public from the controversy", and "instead of trying to restrict the discussion to experts we should indeed extend it to everyone" In this connection I refer to two of my statements: "Probably no technological decision in the history of mankind has been the subject of so many detailed studies, so much open discussion and such broad participation", and "The scale and timing of the introduction of nuclear power is a major and complex decision. In a democratic society such decisions are not left to technological experts but to elected political officials".

Dr Grantham objects to what he calls my "suggested dichotomy: reasonable, rational and valid" versus "irrational, emotional and ethical". Again a quote from my essay is relevant: "Clearly, a number of irrational, emotional and ethical factors may be and should be of importance in a choice of power plants for the production of electricity".

On the role of scientists in public debate, Dr Anfinsen states that "anyone but the most naive petition-signer must understand that sponsors of socioscientific news releases are, and always will be, selected on the basis of the fact that the general public tend to be influenced by lists of the names of "dignitaries" ". This is precisely the basis for my criticism of petition signers using their titles when these are irrelevant to the matter. For example, a responsible nuclear physics professor will know if his personal background justifies him speaking on the nuclear energy question as a nuclear physicist (with a consequent intended and justifield substantial impact on politicians and the public), or if he ought to speak as Mr J. Q. Public. Hence my plea that specialists should not mislead the public by carrying their specialist background as a flag in unrelated issues.

Incidentally, in referring to $\mathrm{E}$. Rabinowitch (for whom I have great respect) as "a person concerning whose judgement and expertise in the area of science and public policy no one would quibble", Dr Anfinsen appears to embrace precisely the authoritarian approach which parts of my essay were directed against.

For Dr Anfinsen, as for myself, the question of a connection between nuclear power and potential nuclear wars is a key issue. It deserves not only the religious and emotional considerations put forward by Dr Anfinsen and the National Council of Churches of Christ in the USA, but also our utmost rational efforts to reduce the risk of such wars, with or without nuclear power. I fail to understand the rationality of distracting public attention from the all important issue of nuclear disarmament by expending substantial efforts on stopping the peaceful uses of nuclear power, which probably decrease rather than increase the risk of war.

Finally, I offer, upon Dr Grantham's request, my definition of rationality: to be rational and reasonable is to apply flexibly the control of our knowledge and our theories to our actions, so that we can perform the continuous trial and error process required for improving our adaptation to the environment by way of critical argumentation, thus reducing the need to subject our physical beings to those vagaries of nature and emotions which are harmful.

The place of facts in the world of human values should be set by the values, but facts cannot be changed by values.

\section{Yours faithfully, JAN M. DODERLEIN}

Institutt for atomenergi,

Kjeller,

Norway

1 Doderlein, J. M., Nature 264, 202 (1976)

Orantham, R., Nature 265, 100 (1977)

3 Anfisen, C.B., Nature 265, 492 (1977)

\section{Requests for reprints}

SiR,-Would you publish an appeal to scientists throughout the world on a matter which is on the one hand extremely trivial but on the other could eliminate a nuisance. I refer to the request for reprints by fellow scientists. Besides the cost of mailing these reprints, it is time consuming to cut out addresses from post cards, glue them onto envelopes, decipher poorly written names and very often have to write the whole address by hand or typewriter. It would make life so much easier if requests in future carried a stick-on label as a few from considerate colleagues already do. Yours faithfully,

Max-Planck-Institut für F. ECKSTEIN

Göttingen, West Germany 